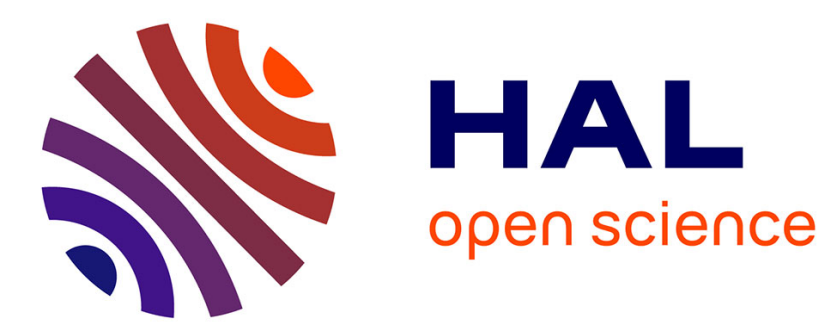

\title{
Premium private labels, supply contracts, market segmentation, and spot prices
}

\author{
Pascale Bazoche, Eric E. Giraud-Heraud, Louis Georges Soler
}

\section{To cite this version:}

Pascale Bazoche, Eric E. Giraud-Heraud, Louis Georges Soler. Premium private labels, supply contracts, market segmentation, and spot prices. Journal of Agricultural and Food Industrial Organization, 2005, 3 (1), pp.1-28. 10.2202/1542-0485.1087 . hal-02669775

\section{HAL Id: hal-02669775 \\ https://hal.inrae.fr/hal-02669775}

Submitted on 31 May 2020

HAL is a multi-disciplinary open access archive for the deposit and dissemination of scientific research documents, whether they are published or not. The documents may come from teaching and research institutions in France or abroad, or from public or private research centers.
L'archive ouverte pluridisciplinaire HAL, est destinée au dépôt et à la diffusion de documents scientifiques de niveau recherche, publiés ou non, émanant des établissements d'enseignement et de recherche français ou étrangers, des laboratoires publics ou privés. 


\title{
Premium Private Labels, Supply Contracts, Market Segmentation, and Spot Prices *
}

\author{
Pascale Bazoche, Eric Giraud-Héraud, and Louis-Georges Soler
}

\begin{abstract}
In recent years, European retailers have modified the market segmentation in the meat and the fresh produce sectors by implementing new private labels which aim to guarantee higher quality and food safety. As a result, retailers impose more demanding production requirements and rely on contractual relationships with upstream producers. Meat and vegetables shelve spaces are now composed of generic products supplied from competitive spot markets, and premium private labels based on long term supply contracts. In this paper we propose a model of vertical relationships between producers and retailers in order to analyze the consequences of such strategies. In particular, we analyze the interest of producers to commit to these new private labels, their effects on spot market prices, and the resulting market segmentation between the spot market and supply contracts.
\end{abstract}

KEYWORDS: retailing, private labels, supply contracts, captive supplies, spot prices

*The authors would like to thank Professor Azzeddine Azzam and two anonymous referees. Their comments and suggestions were very helpful in improving the paper. 


\section{Introduction}

Changes in consumer expectations in terms of product quality and safety have led European distributors over the last few years to profoundly modify their commercial and supply practices in the meat, fruit and vegetables sectors. Faced with insufficient application of public regulations of minimum quality standards, European distributors have as a result created their own certification standards in order to both reassure and strengthen customer loyalty, and develop differentiation strategies in a highly competitive market between retailers.

Firstly, from a commercial point of view, these initiatives have resulted in increased segmentation of products offerings on store shelves. In order to meet the wide range of expectations of consumers, and in particular a fraction of them seeking products of a higher quality, retailers now offer - next to standard products - differentiated products to which they commit themselves not only in terms of stricter controls but also as regards taste, origin and environmental features. These differentiated products are generally sold under the store's brand and are promoted as "premium private labels" (PPL) which are positioned at a higher quality level than unbranded products. Large advertising budgets are allocated to promote these PPL in order to convince consumers of the major efforts made by the retailers.

Secondly, from a supply point of view, these initiatives have resulted in the creation of a new type of relationship with suppliers. Consequently, direct relationships with group of producers are often established on the basis of the application of specific production requirements which enable distributors to become much more involved than before in the suppliers' production processes. Even though distributors may have recourse to wholesale markets for the supply of standard products, the majority of PPL products are based on long-term contractual supply relationships between retailers and producers.

In the United Kingdom, procedures developed in the meat sector by Sainsbury, Marks and Spencer or Tesco are good examples of the new procedures implemented by the European retailers (Fearne, 1998). In France, Carrefour developed the "Carrefour Quality Chains" (CQC). Origin and traceability are the CQC principles, which apply to the meat, fruit and vegetables, fish and seafood sectors. These labels are based on supply agreements with producer groups. In 2003, Carrefour had implemented over 250 partnership agreements with over 35,000 producers (see Codron et al. (2003) and Mazé (2002) for the European experience). Due to its extensive network of outlets in Europe (e.g. France, Spain, Portugal), Carrefour is now focusing on setting up this type of agreement in developing countries and countries in transition.

In any case, this approach is based on production requirements which are more stringent than those imposed by the public authorities. For instance, in the 
case of beef meat at Carrefour, the production specifications are not only aimed at guaranteeing compliance with national laws, but also complete traceability, product safety as well as organoleptic quality of meat. In this respect, in addition to the regulatory aspects imposed by the public authorities, Carrefour certifies that animals belong to a certain breed; specific practices and conditions related to the raising of the animals; feeding based on fodder produced on the farm and approved feed with no hormones or antibiotics. Finally, it guarantees the stringent selection of carcasses after slaughtering in compliance with specific criteria of conformation, fattening, age, weight and a minimum period of maturation for the meat which is higher than for generic products. These production requirements are subject to regular controls performed by third party certification body.

For example, fresh beef meat sold at Carrefour may be divided in two segments as follows:

- The first segment represents approximately $40 \%$ of the market. These products are sold at a low price and are classified as generic goods. They are purchased by the retailer on spot markets without any special agreements with producers.

- The second segment - the PPL segment - represents the remaining market. These products are purchased from producers groups committed to application of more demanding production requirements and are sold at a price $10 \%$ to $20 \%$ higher than the generic products.

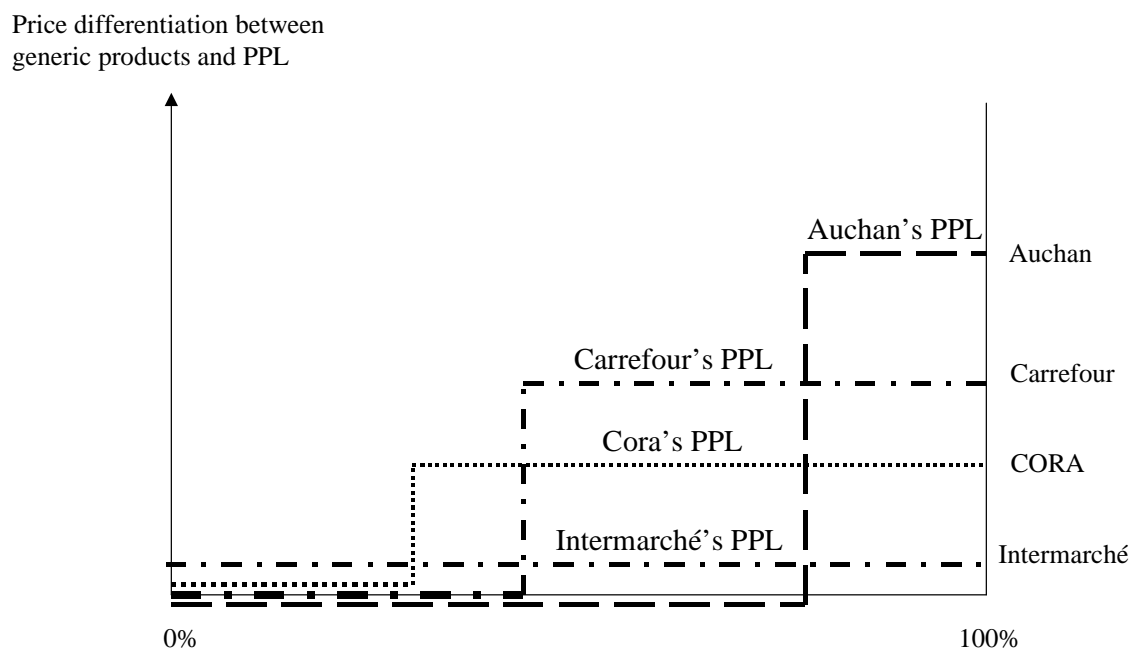

Figure 1 - Market segmentation for beef meat in 4 French stores (Source : INRA data) 
As Figure 1 shows for the French case, the balance between standard product and PPL in the shelf space varies from retailer to retailerare. However, in all cases, distributors base their communication policy on the PPL segment, thereby guaranteeing to the consumers the stringency of the controls conducted throughout the supply chain and the quality features of the product to the consumer.

In exchange for the application of the production requirements, Carrefour commits itself to a price premium in relation to the spot market prices. Producers are paid on the basis of the average weekly spot prices, to which are added some premiums mainly linked to compliance with production requirements. As shown if Figure 2, the resulting prices follow the fluctuations of wholesale reference markets which allow the retailer to avoid a risk of contract termination if the spot market prices rise, and to remain aligned with the supply costs of its competitors if the spot market prices decrease.

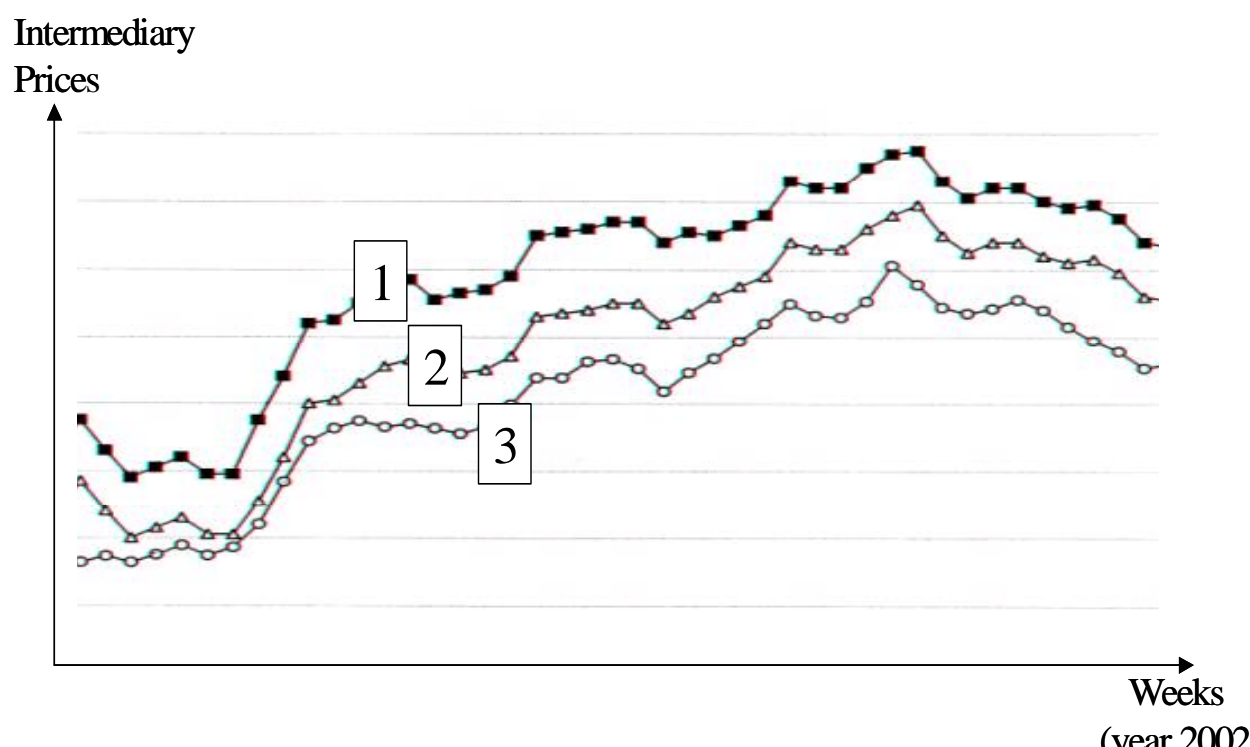

Figure 2 -Beef meat prices paid to the producers in Normandy in 2002: Carrefour's PPL (1), regional wholesale market (2), national wholesale market (3)

Through these initiatives, retailers become leaders in the reorganization of agricultural chains by favoring the grouping of upstream producers and more demanding production requirements than those imposed by public authorities. The initiatives also gave rise to contracting directly producers.

\footnotetext{
${ }^{1}$ Several past studies have indeed shown the difficulties induced by information asymmetry concerning the efforts made by producers and the hold-up risks which may result (Hennessy, 1996 and 1998; Boehlje and Shrader, 1998; Gallizi and Venturini, 1999; Ziggers and Trienekens, 1999; Boger, 2001; Vetter and Karantininis, 2002). In the case of PPL, the implementation of contracts is
} 
The goal of our paper is to analyze these new private labels which aim to segment the market of fresh produce and meat and increase the quality level in sectors in which producers are atomistic and not able to implement strong national brands. We propose a model of a vertical relationship between producers and retailers in order to answer the following questions: is it in the interest of producers to commit to these new procedures? Does PPL implementation have an effect on spot market prices? How are these prices influenced by the quality choice of PPL ? How does the retailer segment the market between to spot purchases and supply contracts? In order to answer these questions, it is necessary to determine the optimal allocation of the market between the standard products and the premium private labels in relation with the price formation in the intermediary markets, and the quality level of the PPL and its effect on the strategic games within the vertical structure.

It is important to note that the substitution - even partial - of contractual relationships to traditional supplies on spot markets necessarily results in a loss of flexibility for the retailers. Consequently, the market segmentation depends on the trade-off between broadening the range of products subject to stricter requirements, which means more contractual relationships with producers, and keeping the highest degree of flexibility vis-à-vis the suppliers by risking to offer only generic products which do not meet expectations of some consumers.

The first important dimension to consider in analyzing this trade-off is the effect of the co-existence of spot markets and supply contracts on retailers' strategies. Apart from the strategic alternatives it allows for each stakeholder, this co-existence can influence the price formation on the intermediary markets. Several articles in the literature have dealt with the interaction between spot market prices and captive supply prices. For instance, Elam (1992) and Schroeder et al. (1993) show a negative relationship between captive supplies and spot market prices. The explanation is simple: when contracts increase, the demand on free markets can decrease more than the supply so that the prices on the spot market are affected. Ward et al. (1998) also find a negative relationship between transaction prices and the percentage deliveries from contractual agreements, but not between transaction prices and the absolute size of the captive supply inventory. However, they conclude that in general the relation is ambiguous and depends upon the functional forms of demand and supply. Other articles deal with competitive impacts of industry concentration on spot market prices. Love and Burton (1999) show that the spot market price is affected by the concentration of upstream firms and the price can rise or fall depending on the residual elasticity of raw material supply. Azzam (1998) re-examines this relationship within the

a way to influence the production processes in order to increase quality level and, at the same time, to reduce the risks of moral hazard related to information asymmetry in the producer-retailer relationship. 
context of a formal economic model in order to assess the non-competitive effects of captive supplies. He shows that the sign of the relationship is ambiguous and a negative relationship between spot market prices and supply contracts (or upstream integration) may not be a consequence of noncompetitive conduct downstream. He cautions against the conclusions drawn from the empirical literature and points out that other factors must be taken into account, such as the type of contractual price agreements (for instance when the contract price is not equivalent to the marginal cost of captive supplies). If there is a relationship between the extent of contracts and the spot market price, the contracts can be implemented by the downstream buyers in order to influence the spot market price. In order to assess this point, Zhang and Sexton (2000) propose a spatial model and show that processors can use exclusive contracts to manipulate the spot market prices in certain situations. Xia and Sexton (2004) study the competitive implications of contractual agreements when these contracts are linked to the cash market price. In their model, price-taking producers have to trade off between contract and cash market according to the contractual price, and the quantity sold on the cash market depends on the cash market price. The authors show that with certain type of contracts, buyers' to compete aggressively on the spot market are decreased.

The second dimension that must be taken into account is the role of private labels within the vertical structure and the link between private label quality and supplier-retailer relationships. Extensive literature exists as private labels have taken on considerable importance over the past twenty years in most developed countries. Bergès-Sennou et al. (2004) provide a survey of the economic literature dealing with private labels in the food sector. The aim of most of what has been written is to understand the competitive interaction between private label and producers' brands (see Mills, 1995, 1999). They examine to what degree these procedures create value and how, depending on the case, this value is shared among the various stakeholders. Some of the literature puts emphasis on the differentiation strategy choice and examine the quality and price positioning of the store brands compared to the existing national brands (Connor and Peterson, 1992; Slade, 1995; Raju et al., 1995; Bontems et al., 1999; Corstjens and Lal, 2000). Other literature focuses on empirical determinants of market shares and estimation of price interactions between private labels and manufacturers' brands (Cotteril et al., 2000). Results show power shifting to the retailers and private labels are positioned at lower retail prices and quality levels than the national brands, or act as close substitutes to these national brands. However, Dunne and Narasimhan (1999) give the example of Loblaws, the largest Canadian Grocery, which added the new Premium President's Choice line to its traditional unbranded products. The marketing messages of Loblaws stress the quality of the ingredients and the preparation of President's Choice. Its olive oil, for example, is claimed to be "harvested from trees planted more than 80 years ago and produced from the 
first cold pressing of sun ripened olives", which means higher quality and production costs. It is exactly the same type of marketing messages which are used by the retailers in the meat and fresh produce sectors about the quality, safety and environmental guarantees given by PPL.

The contribution of our paper, which builds on the work by Giraud-Héraud et al. (2003) is twofold. First, the paper establishes the link between market allocation and supply chain organization. Second, it considers product differentiation when analyzing the interaction between spot market prices and supply contracts. In section 2, we present the benchmark situation in which retailers sell only one product supplied through the spot market. After that, we consider one retailer who decides to implement a higher quality product than the generic one. We assume that this retailer is able to sell two products which are supplied through two different channels: the generic quality channel which supplies all the retailers through a spot market fed by the whole group of producers; and the PPL channel based on a specific relationship with a subset of producers and aimed at developing the higher quality product. The relationship between the retailer and the group of producers is intended to give credible guarantees to the consumers in terms of quality and food safety. In section 3 , we present some results based on numerical simulations. We analyze the variation of the spot market price and the PPL market share according to the PPL quality level, calculate the profits of the different stakeholders, and determine the optimal quality of the PPL. We show that the creation of the higher quality private label can increase the spot market prices relatively to the benchmark situation. We also show that, although producers and retailers may not agree on the choice of PPL quality, the PPL, contrary to past findings in the literature, are not detrimental for the upstream producers. In the conclusion we discuss these results in relation to the agreement between Carrefour and meat producers in Normandy. Finally, we propose some extensions to the model.

\section{The Model}

\subsection{Benchmark Analysis}

Consider a set of $J$ producers offering an identical product represented by a onedimensional parameter $k_{0}>0$. Denote by $C\left(k_{0}, q\right)$ the production cost paid by the producer $j$ for the quantity $q$ and the quality $k_{0}$. For our purposes, we consider the following functional form for cost function:

$$
C(k, q)=c(k) q^{2} \text {. }
$$

The parameter $c(k)$ measures the production cost for a given level of quality $k$. Costs are assumed to be increasing in $k$, with $c^{\prime}()>$.0 and $c^{\prime \prime}()>$.0 . This also implies than an increase in $k$ leads to lower output. 
We assume that the product $q$ with quality $k_{0}$ is marketed in the vertical structure shown in Figure 3. Each producer is a price-taker and supplies an intermediary market (hereafter "spot market"). $R$ retailers buy the quantities they need on this spot market and sell the final goods in a market of size $M$. For simplicity, we assume each retailer $r(r=1, \ldots, R)$ has a local monopoly ${ }^{2}$. Although we assume a retailer is a local monopolist when it sells to consumers, we consider that the retailer behaves as an oligopsonist when it buys from the $J$ producers.

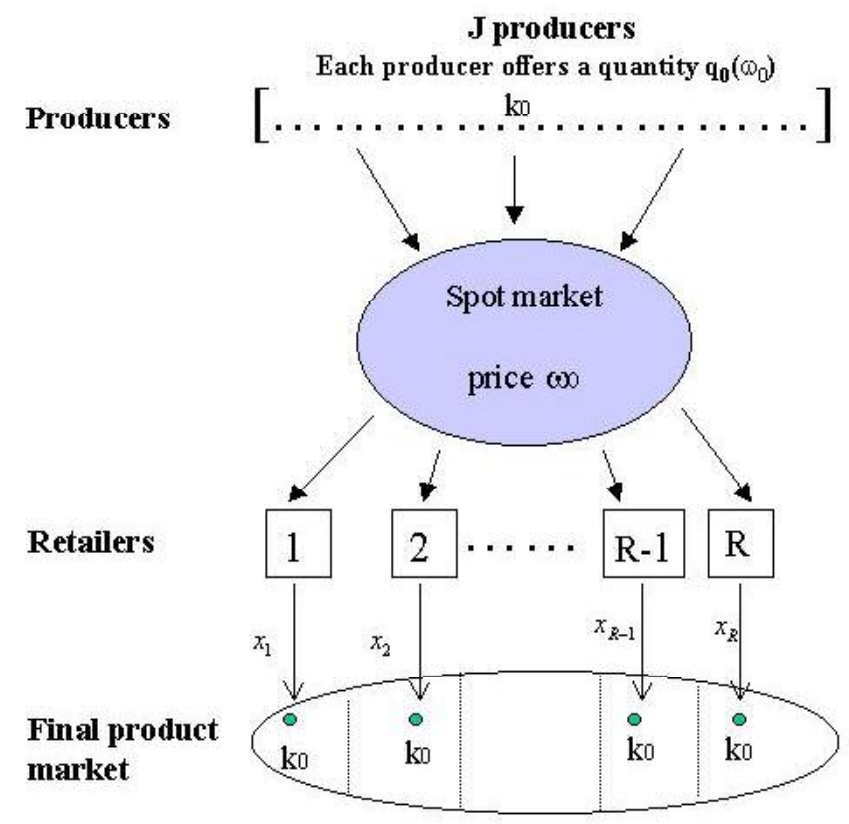

\section{Figure 3 - Chain Structure without Premium Private Label}

Consumer demand in each downstream market is assumed to be vertically differentiated as in Mussa and Rosen (1978). In each market of size $M$, each consumer buys one unit of the good. Consumers are distinguished by a onedimensional taste parameter $\theta$. We assume that $\theta$ is uniformly distributed over the interval $[0, \bar{\theta}]$ with the density $f(\theta) \equiv 1 / \bar{\theta}(\bar{\theta}$ is similar for all the markets of

\footnotetext{
${ }^{2}$ This assumption is justifiable when consumers choose the store according to general features such as location, product diversity and general level of prices and quality, and not by comparing the offers of the different retailers for each specific product (see, for example, Chardon and Dumartin (1998) for the French market). This means that it is not relevant for our purposes to assume a price competition for each specific product between the different supermarket chains. However, the model we propose will not be entirely applicable if one wants to take into account competition between retailers.
} 
all the retailers). The surplus of a consumer of type $\theta$ buying one unit of quality $k_{0}$ at price $p_{0}$ is given by the expression $S(\theta)=\theta k_{0}-p_{0}$. Only those consumers having a positive surplus (e.g. $\left.\theta>\left(p_{0} / k_{0}\right)\right)$ buy the product. Hence, the total demand for each retailer $r$ is $d_{r}\left(k_{0}, p_{0}\right)=[M / \bar{\theta}]\left[\bar{\theta}-\left(p_{0} / k_{0}\right)\right]$. It follows that the inverse demand, as a function of retail quantity $x_{r}$, can be written as:

$$
p_{0}=\frac{\bar{\theta} k_{0}}{M}\left(M-x_{r}\right) \text {. }
$$

This assumes that each retailer converts the raw material product $q$ into a finished product $x$ according to a fixed-proportions production function $(x=q)$. Profits of retailer $r$ buying quantity $x_{r}$ at price $\omega_{0}$ and selling it at price $p_{0}$ on the downstream market is $\Pi_{r}\left(x_{r}\right)=\left(p_{0}-\omega_{0}\right) x_{r}$. Optimal quantity $x_{r}$ placed on the market is obtained by maximizing this profit and taking into account the effects on both the retail prices and the intermediary prices.

Taking into account that each upstream producer is a price taker, the profit of each producer $j(j=1, \ldots, J)$ is $B_{j}\left(k_{0}, q\right)=\omega_{0} q-C\left(k_{0}, q\right)$. Using (1), one obtains the individual supply function $q=\omega_{0} / 2 c_{0}$ (with $c_{0}=c\left(k_{0}\right)$ ) and the spot market supply function is $Q=J \omega_{0} / 2 c_{0}$. The profit of each producer $j$ is then given by $B_{j}\left(\omega_{0}\right)=\left(1 / c_{0}\right)\left(\omega_{0} / 2\right)^{2}$.

We consider the game in which retailers compete in quantity on the final market and choose simultaneously their output and their input. The $R$ retailers decide the quantities $x_{r}(r=1, \ldots, R)$ by anticipating the effect on the final price (using (2)) and the effect on the intermediary price $\omega_{0}$.

Considering the market clears when $Q=\sum_{r=1}^{R} x_{r}$, this intermediary price is obtained by:

$$
\omega_{0}=\frac{2 c_{0}}{J} \sum_{r=1}^{R} x_{r} .
$$

Using (2) and (3), the first-order conditions from maximizating of $\Pi_{r}\left(x_{r}\right)$ are:

$$
\frac{\partial \Pi_{r}\left(x_{r}\right)}{\partial x_{r}}=\bar{\theta} k_{0}-\frac{2 c_{0}}{J} \sum_{i \neq r} x_{i}-2 x_{r}\left(\frac{\bar{\theta} k_{0}}{M}+\frac{2 c_{0}}{J}\right)=0 \quad r=1, \ldots, R .
$$


By solving the system (4) of $R$ equations, we obtain a unique equilibrium where all the quantities $\bar{x}_{r}$ are identical:

$$
\bar{x}_{r} \equiv x=\frac{\bar{\theta} k_{0} J M}{2\left[c_{0} M(R+1)+\bar{\theta} k_{0} J\right]} \quad r=1, \ldots, R
$$

Using (2) and (3), we obtain the spot market price and the final product price of quality $k_{0}$ :

$$
\mid \begin{aligned}
& \omega_{0}=\frac{2 c_{0} x R}{J}=\frac{c_{0} \bar{\theta} k_{0} J M R}{c_{0} M(R+1)+\bar{\theta} k_{0} J} \\
& p_{0}=\frac{\bar{\theta} k_{0}(M-x)}{M}=\frac{\bar{\theta} k_{0}}{2}\left[\frac{2 c_{0} M(R+1)+\bar{\theta} k_{0} J}{c_{0} M(R+1)+\bar{\theta} k_{0} J}\right]
\end{aligned}
$$

From (6), the gross margin is $p_{0}-\omega_{0}=\left(\bar{\theta} k_{0} J+2 c_{0} M\right)(x / J M)$ and, the equilibrium profits are:

$$
\mid \begin{array}{ll}
\bar{\Pi}_{r}=\left[\frac{\bar{\theta} k_{0} J+2 c_{0} M}{J M}\right] x^{2} & r=1, \ldots, R \\
\bar{B}_{j}=c_{0}\left(\frac{R x}{J}\right)^{2} & j=1, \ldots, J
\end{array}
$$

Consumers' surplus for the clientele of retailer $r$ is given by:

$$
\bar{W}_{r}=M \int_{\bar{p}_{0} / k_{o}}^{\bar{\theta}}\left(\theta k_{0}-\bar{p}_{0}\right) f(\theta) d \theta=\frac{M}{2 \bar{\theta}}\left(\bar{\theta}-\frac{\bar{p}_{0}}{k_{0}}\right)^{2}=\frac{\bar{\theta} k_{0} x^{2}}{2 M}
$$

Equations (7) and (8) define the benchmark issue to which the situation with the PPL will be compared. We will now examine whether quality and surpluses are altered through the creation of this type of private label.

\subsection{Vertical Relationship with Premium Private Label}

We study the vertical structure shown in Figure 4. We consider that one of the retailers (retailer $R$ without loss of generality) carries a PPL with quality $k_{1}$ that is higher than $k_{0}$. Retailer $R$ also buys a quantity $x_{R}$ of low quality product $k_{0}$ on the spot market (at the price $\omega_{0}$ which can be different from the spot market price calculated in the previous section) and gets quantity $y_{R}$ of higher quality product 
$k_{l}$. This quantity $y_{R}$ is supplied by a subset of $G$ producers $(G \leq J)$ contracting with retailer $R$. This group of producers is supposed to have no bargaining power except the ability to accept or reject the retailer's proposal. The decision to accept or reject retailer $R$ 's demand depends on the PPL intermediary price $\omega_{1}$ of the PPL and production $\operatorname{cost} c_{1}=c\left(k_{1}\right)$.

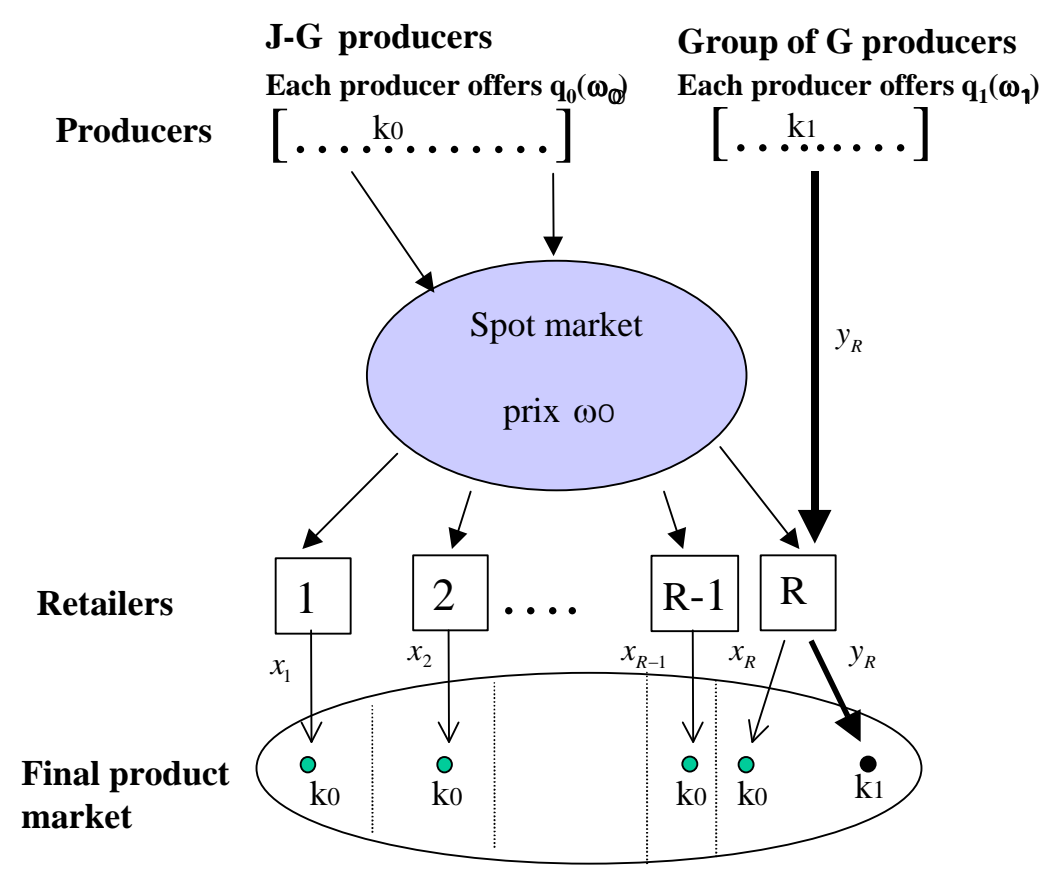

Figure 4 - Chain Structure with Premium Private Label

Downstream markets of the $R-1$ retailers are the same as in the benchmark situation (they are assumed to only market quality $k_{0}$ ). Concerning retailer $R$, demand functions must be calculated by taking into account the two qualities offered to the consumers. Each consumer of taste $\theta$ chooses the standard product of quality $k_{0}$ (priced at $p_{0}$ ) rather than the PPL of quality $k_{l}$ (priced at $p_{l}$ ) if $\theta k_{0}-p_{0}>\theta k_{1}-p_{1}$ (i.e., if $\left.\theta<\hat{\theta}=\left(p_{1}-p_{0}\right) /\left(k_{1}-k_{0}\right)\right)$. Thus, the demand functions for qualities $\left(k_{0}, k_{l}\right)$ sold at prices $\left(p_{0}, p_{l}\right)$ to the $M$ consumers by retailer $R$, are: 


$$
\mid \begin{aligned}
& d_{0}\left(k_{0}, k_{1}, p_{0}, p_{1}\right)=\frac{M}{\bar{\theta}}\left(\frac{p_{1}-p_{0}}{k_{1}-k_{0}}-\frac{p_{0}}{k_{0}}\right) \\
& d_{1}\left(k_{0}, k_{1}, p_{0}, p_{1}\right)=\frac{M}{\bar{\theta}}\left(\bar{\theta}-\frac{p_{1}-p_{0}}{k_{1}-k_{0}}\right)
\end{aligned}
$$

We obtain the downstream market prices $p_{0}$ and $p_{l}$ charged by retailer $R$ to its consumers for qualities $k_{0}$ and $k_{l}$ by inverting the system in (9):

$$
\mid \begin{aligned}
& p_{0}=\frac{\bar{\theta} k_{0}}{M}\left(M-x_{R}-y_{R}\right) \\
& p_{1}=\frac{\bar{\theta}}{M}\left(k_{1} M-k_{0} x_{R}-k_{1} y_{R}\right)
\end{aligned}
$$

Equations (10) represent the inverse demand function for retailer $R$ when both qualities $k_{0}$ and $k_{1}$ are supplied. Retailer $R$ 's profit and consumers' surplus are given by:

$$
\mid \begin{aligned}
& \Pi_{R}=\left(p_{0}-\omega_{0}\right) x_{R}+\left(p_{1}-\omega_{1}\right) y_{R} \\
& W_{R}=\frac{\bar{\theta}}{2 M}\left[k_{0} x_{R}^{2}+k_{1} y_{R}^{2}+2 k_{0} x_{R} y_{R}\right.
\end{aligned}
$$

Similarly to Xia and Sexton (2004), and given the particular structure of Figure 4, the game evolves in two stages. In Stage I, each producer decides whether to sell on the contract market or on the spot market. Then retailer $R$ decides the quantity to purchase in order to supply the PPL. In Stage II, the R retailers compete in quantity and decide how much to buy on the spot market. The upstream producers, who do not sell through the PPL, sell their product on the spot market. The game is solved using backward induction.

Suppose at Stage II $G$ producers have elected to sell their product on the PPL market and that the PPL intermediary price $\omega_{1}$ and the quantity $y_{R}$ are fixed. As previously mentioned, we obtain the new spot market price by calculating the quantities bought by the retailers on this market. We assume that the quantities correspond to the equilibrium of the simultaneous game between the retailers.

In order to obtain more compact equations, we introduce the following notation: 


$$
\mid \begin{aligned}
& \alpha=\frac{c_{0}}{\bar{\theta} \mathrm{k}_{0}(J-G)} \\
& \beta=\frac{c_{1}}{\bar{\theta} \mathrm{k}_{1} G}
\end{aligned}
$$

Using (4), we have the following first order condition for maximization of the first $R-1$ retailers' profits (i.e the retailers who do not take part in the PPL).

$$
\frac{\partial \Pi_{r}}{\partial x_{r}}=\bar{\theta} k_{0}-\frac{2 c_{0}}{J-G} \sum_{i \neq r} x_{i}-2 x_{r}\left(\frac{\bar{\theta} k_{0}}{M}+\frac{2 c_{0}}{J-G}\right)=0 \quad r=1, \ldots, R-1
$$

The profit of retailer $R$ is given by (11) where $\omega_{1}$ is fixed, $p_{0}$ and $p_{1}$ are given by (10) and $\omega_{0}$ is given by:

$$
\omega_{0}=\frac{2 c_{0}}{J-G} \sum_{i=1}^{R} x_{i}=2 \bar{\theta} k_{0} \alpha \sum_{i=1}^{R} x_{i}
$$

As a result, the first order condition for retailer $R$ is:

$$
\frac{\partial \Pi_{R}}{\partial x_{R}}=\frac{\bar{\theta} k_{0}}{M}\left(M-2 x_{R}-2 y_{R}\right)-\frac{2 c_{0}}{J-G}\left(\sum_{i \neq R} x_{i}+2 x_{R}\right)=0
$$

Using (13) and (15) the equilibrium $\left(x_{1}, \ldots, x_{R}\right)$ of the sub-game of stage II can be found by the solution of the following system:

$$
\left\{\begin{array}{l}
1-2 \alpha \sum_{i \neq r} x_{i}-2 x_{r}\left(\frac{1}{M}+2 \alpha\right)=0 \quad r=1, \ldots, R-1 \\
\frac{1}{M}\left(M-2 x_{R}-2 y_{R}\right)-2 \alpha\left(\sum_{i \neq R} x_{i}+2 x_{R}\right)=0
\end{array}\right.
$$

The system of equations in (16) is solved using the symmetric property that $x_{r}$ is the same for all $r=1, \ldots, R-1$. By virtue of the symmetry the system in (16) can be rewritten as:

$$
\left\{\begin{array}{l}
M-2 \alpha M\left[(R-2) x_{r}+x_{R}\right]-2 x_{r}(1+2 \alpha M)=0 \quad r=1, \ldots, R-1 \\
M-2 x_{R}-2 y_{R}-2 \alpha M\left[(R-1) x_{r}+2 x_{R}\right]=0
\end{array}\right.
$$


Hence, for a fixed $y_{R}$, the quantities equilibrium in the sub-game of retailers competition on the spot market are:

$$
\left\{\begin{array}{l}
x_{r}=\frac{M\left(1+\alpha M+2 \alpha y_{R}\right)}{2(1+\alpha M)(1+\alpha M+\alpha M R)} \quad r=1, \ldots, R-1 \\
x_{R}=\frac{M(1+\alpha M)-2 y_{R}(1+\alpha M R)}{2(1+\alpha M)(1+\alpha M+\alpha M R)}
\end{array}\right.
$$

Using (18), the total (derived) demand on the spot market is:

$$
D=(R-1) x_{r}+x_{R}=\frac{M R-2 y_{R}}{2(1+\alpha M+\alpha M R)} .
$$

Setting $D=\left[\omega_{0}(J-G)\right] / 2 c_{0}$ (supply from independent producers), we then find the spot market price as a function of quantity $y_{R}$ commercialized on the PPL:

$$
\omega_{0}=\frac{\bar{\theta} k_{0} \alpha\left(M R-2 y_{R}\right)}{(1+\alpha M+\alpha M R)}
$$

At stage I, retailer $R$ maximizes its profit by choosing $y_{R}$. By equalizing supply and demand on the intermediary PPL market, and using (12) we obtain the contractual price:

$$
\omega_{1}=2 \bar{\theta} k_{1} \beta y_{R} .
$$

Now eith $\left(\omega_{0}, \omega_{1}\right)$ given by $(20)$ and $(21) ; x_{R}$ by $(18)$ and $\left(p_{0}, p_{1}\right)$ by (10), we can determine the equilibrium profit given by (11). Maximizing $\Pi_{R}$ and solving for $y_{R}$ yields:

$$
y_{R}=\frac{M(1+\alpha M)\left[k_{1}(1+\alpha M+\alpha M R)^{2}-k_{0}(1+2 \alpha M)(1+\alpha M R)\right]}{2 k_{1}(1+2 \beta M)(1+\alpha M)^{2}(1+\alpha M+\alpha M R)^{2}-2 k_{0}(1+2 \alpha M)(1+\alpha M R)^{2}}
$$

Equation (22) gives the PPL quantity supplied by retailer $R$. Given that quantity, we can calculate the quantities supplied on the spot market, using (18), and the intermediary prices $\omega_{0}$ and $\omega_{1}$, using (20) and (21). Thus, the producers in the first stage, anticipating these prices, have to choose between the spot market or the PPL. If we consider a simple procedure where the producers enter simultaneously into the group, a Nash equilibrium of this game is defined by a specific value $G^{*}$ such that it is not in the interest of any member of the set of $G$ producers to move to the spot market and no producer remaining outside of the set 
of $G$ producers will find any interest in moving to the PPL contract ${ }^{3}$. When $J$ is large enough, combined with the assumptions of price-taking upstream, it is clear that $G^{*}$ is the percentage of producers in the PPL such as the profits in the spot market and in the PPL are identical. The existence of $G^{*}$ is uncertain. In the next section we simulate the effects of the creation of the PPL under different scenarios for $G^{*}$ by calibrating the model to a real market of PPL We chose a simulation because not all effects can be solved for analytically.

\section{Effects of the creation of PPL: Simulation Results}

The data used for the simulation come from a study concerning a PPL set up by Carrefour and an agreement between this retailer and a group of meat beef producers in Normandy (France). The model presented in section 2 has been calibrated on the basis of marketed quantities, retail prices, and intermediary prices observed in this real case. The market size $M$ is given by the greatest quantity marketed by the beef producers in Normandy between 2000 and 2003. Five thousand producers are involved in the contract, the purpose of which is to supply beef to 122 Carrefour stores. The intermediary prices are the spot market prices in Normandy and the contractual prices correspond to the prices paid by Carrefour to the group of producers (see Figure 2 in section 1). The PPL specification leads to production costs higher than that of the standard product. In 2003, the premium paid to the producers was around 0.15 euros per kilo. The quantities are those marketed by Carrefour in the stores in 2003: between 55\% of the shelf space was dedicated to the PPL, and between $45 \%$ to the standard product. The retail price differential between the two products was around $15 \%$. The Carrefour agreement, which has been described in Mazé (2002), led to several conflicts between the producers and the retailer, especially about the production specification and, thus, the quality level of the products marketed through the PPL channel. For this reason, the analysis is focused on the impact of PPL quality level on the stakeholders' profits. This question is not trivial. Indeed, if the retailer chooses the PPL quality, he has to anticipate the number of producers willing to enter the PPL agreement, taking into account that this entry modifies the economic equilibrium within the chain. In the following, simulations are conducted in order to get a better understanding of these mechanisms. The quality levels considered in the simulations are defined in order to explore a range of realistic levels of consumers' willingness to pay for beef meat.

We begin by analyzing the benchmark situation and present the stakeholders' profits according to the standard product quality (subsection 3.1).

\footnotetext{
${ }^{3}$ As noted by one referee, if one interprets the first stage of the game as a choice of quality by the producers, then a hold-up problem can arise. Especially when final demand is uncertain, producers who incurred higher quality costs could end up selling on the spot market. It would be interesting to analyze this effect with a model with demand uncertainty.
} 
After that, we analyze the impact related to the creation of the PPL. Our focus is on how $G$ changes with the change in the quality level of the PPL, and on how retailer $R$ segments the market (subsection 3.2). Next, we also show how the final and intermediary prices change with the change in the quality level of the PPL (subsection 3.3) and their implications for stakeholders' profits (subsection 3.4). The results are followed by a discussion and suggestions for further research.

\subsection{Profits in the benchmark situation}

We assume that the quality cost function follows the specification: $c(k)=k^{\alpha}$ $(\alpha>2)$. This assumption is common in many models of vertical differentiation of quality (e.g. Champsaur and Rochet (1989) and Motta (1993) where quality yields decrease). Indeed, when $\alpha \leq 2$, producers' profits are strictly increasing in the quality level. This assumption would not be realistic as it would mean that the producers always benefit from increasing the product quality.

As shown in Figure 5, the profits obtained by the stakeholders in the benchmark present the following features:

- the optimal standard product quality is greater for the retailers than for the consumers

- the optimal standard product quality is greater for the producers than for the retailers.

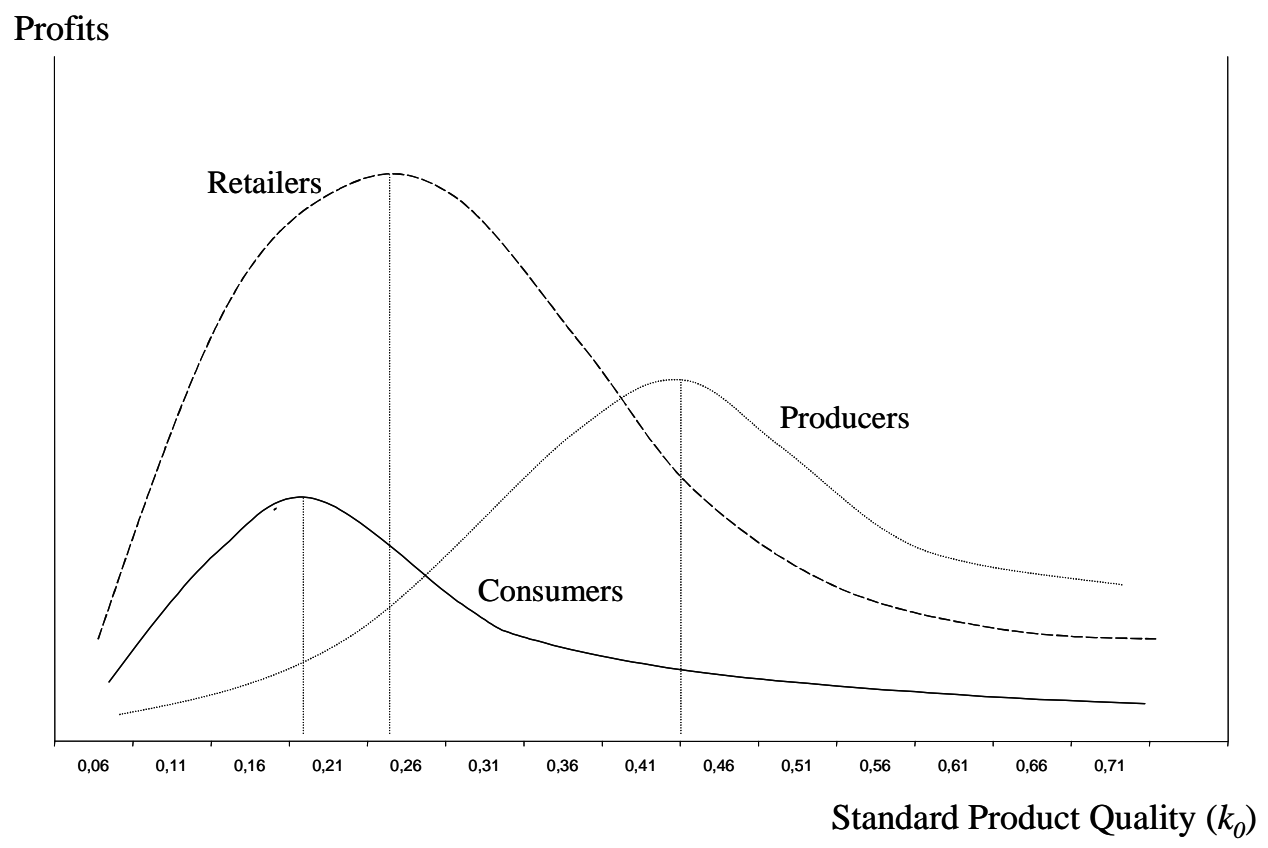

Figure 5 - Benchmark Profits and Surplus according to Standard Product Quality 
What generates the results is the fact that the retail prices increase faster than the intermediary prices when the standard product quality increases (given the cost function and the Mussa-Rosen demand function).

\subsection{Formation of $\mathbf{G}$ and market segmentation}

As shown in section 2, the quantities marketed by retailer $R$ and the intermediary and final prices depend on the size $G$ of the group of producers. Before determining quantities and prices, we have to define this parameter. As mentioned above, at the equilibrium, the size $G^{*}$ of the group of producers is such that the profits of producers inside and outside this group are equal, i.e., $\omega_{1}=\omega_{0} \sqrt{c_{1} / c_{0}}$. Figure 6 shows the variations of $\omega_{0} \sqrt{c_{1} / c_{0}}$ and $\omega_{1}$ according to PPL quality and determine the endogenous value $G^{*}$ of producers involved in the PPL agreement at the game equilibrium.

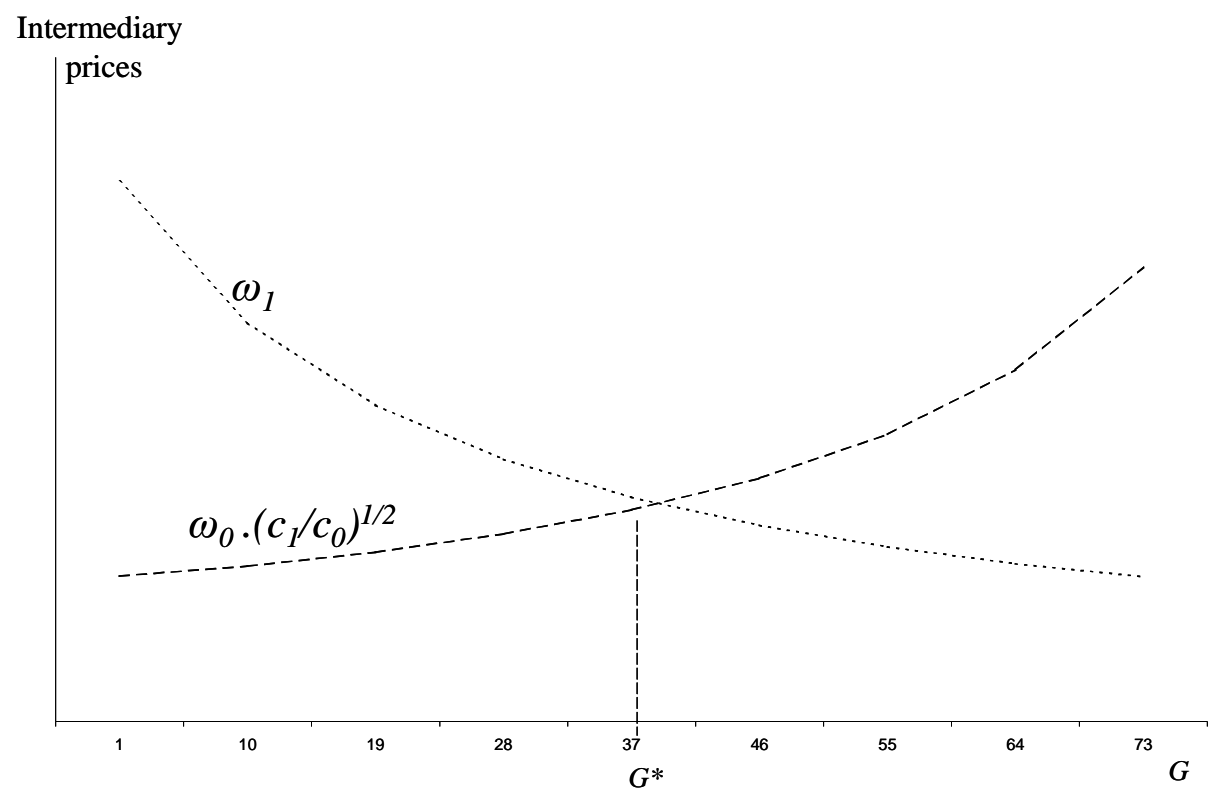

Figure 6 - Intermediary prices according to the size of the producers group

First, $G^{*}\left(k_{1}\right)$ is decreasing in $k_{0}$ because when the standard product quality increases, it is less and less in the interest of the producers to take part in PPL production. The reason is because the spot price increases. Indeed, when $k_{0}$ increases each producer, who does not participate in the PPL market, reduces his own supply (due to the cost increase). In our simulation model, because of the 
high number of standard quality producers, this effect leads to a strong spot market price increase, making producer participation in PPL less attractive.

Secondly, for a fixed $G$, the intermediary prices $\omega_{0}$ and $\omega_{1}$ increase when the PPL quality increases. On the one hand, it is obvious that when $k_{1}$ increases, the strong supply reduction of the PPL, due the convexity of the cost curve, leads to an increase in the PPL intermediary price. On the other hand, the PPL intermediary price induces the retailer $\mathrm{R}$ to substitute the standard product for the PPL, leading to a demand increase on the spot market which favors an increase in the spot market price. For these reasons, $G^{*}$ depends on two opposing effects. When $k_{1}$ increases, the $\omega_{1}$ curve moves to the right whereas the $\omega_{0}$ curve moves to the left. These two effects explain the existence of a maximum value of $G^{*}$ when PPL quality increases (see Figure 7 for 3 values of standard product quality ). All simulation results presented in the rest of the paper are given for $G^{*}\left(k_{1}\right)$.

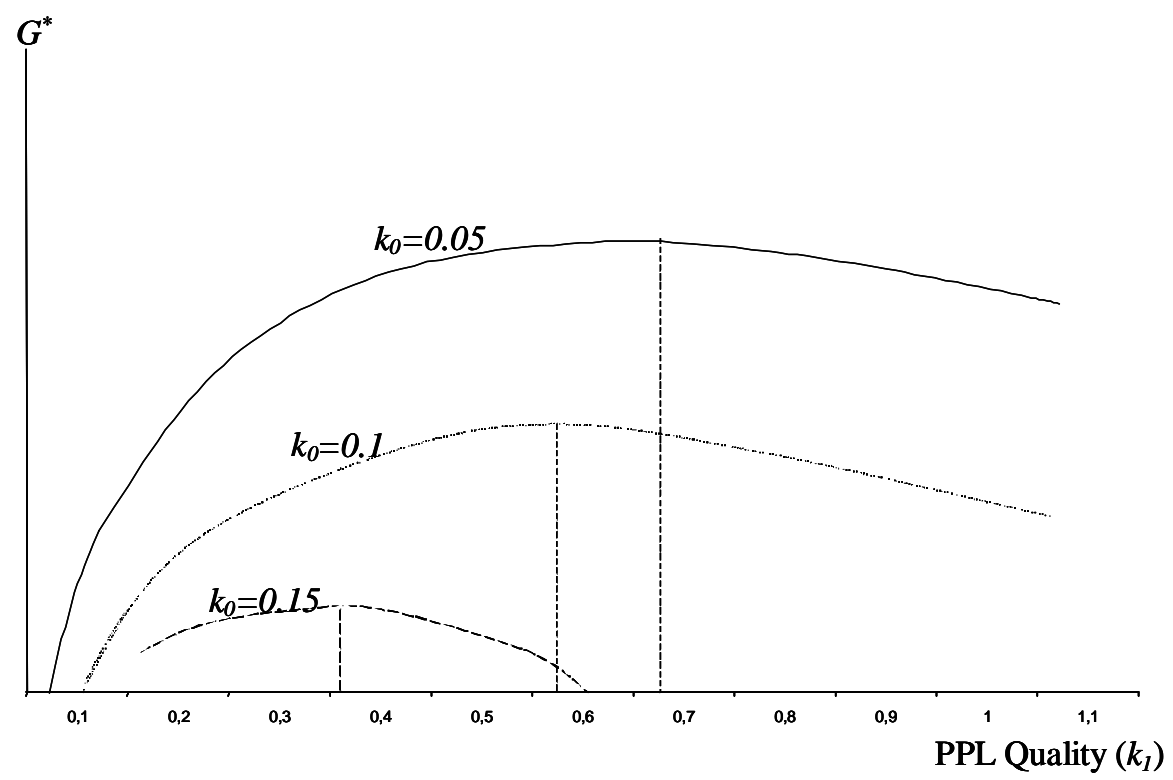

Figure 7 - Size of Group of Producers according to PPL and Standard Product Qualities

As mentioned before, the main issue for the retailer is to determine the best way to supply the market given the product qualities available at the upstream level and the consumers' willingness to pay. Figure 8 shows how retailer $R$ modifies the balance between the two products according to the private label quality $k_{1}$ and for $G=G^{*}\left(k_{1}\right)$. If $k_{1}$ is close to $k_{0}$, retailer $R$ mainly markets the premium private label. In this case, a large share of retailer $R$ 's market is dedicated to the PPL but at a quality level very close to the standard product. This effect is modified when $k_{l}$ is much higher than $k_{0}$. In this case, it is more 
advantageous to decrease the market share allocated to the private label and to favor the unbranded product. Even if the PPL quality is very high, the retailer's supply strategy becomes more similar to its benchmark strategy because the largest share of the market is dedicated to the standard product.

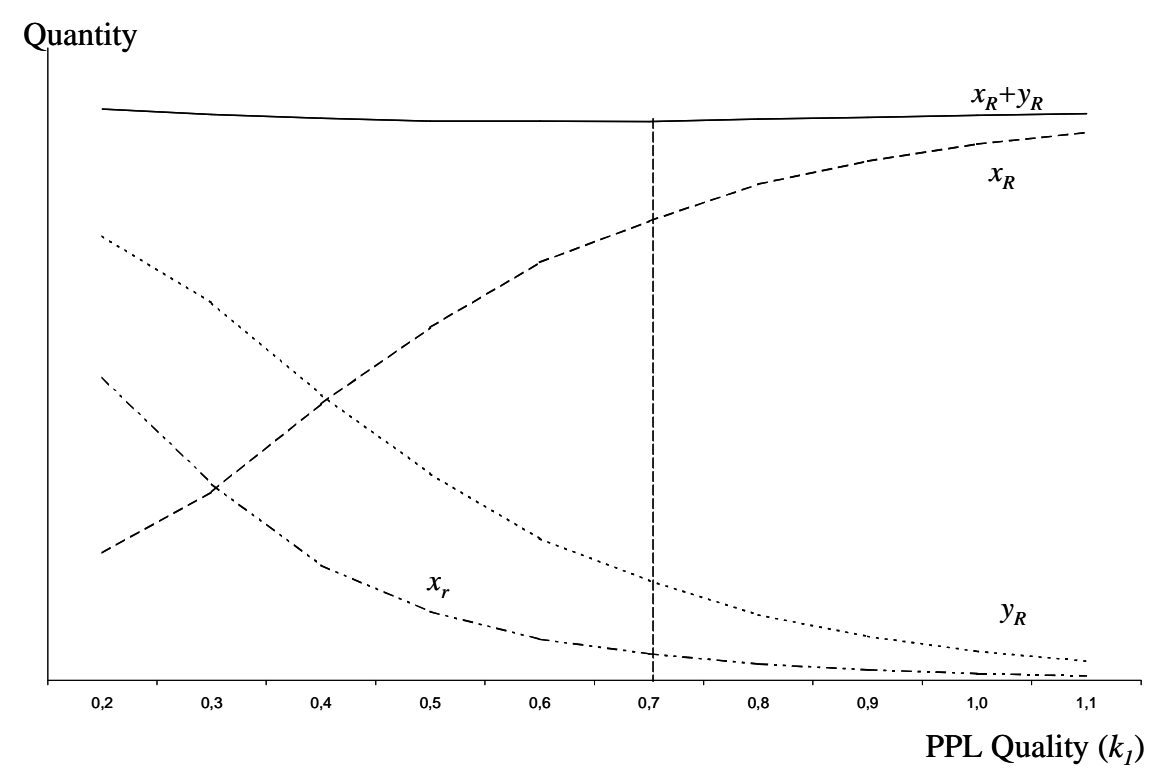

Figure 8 - Market segmentation by Retailers

\subsection{Retail and intermediary prices}

It goes without saying that the PPL retail price increases when its quality increases too. As shown in Figure 9, the final price of the standard product is higher than in the benchmark because of the decrease in volume. Nevertheless, the price level depends on the demand faced by all retailers. For retailers $r(r=1, \ldots$, $R-1)$, the retail price of the standard product increases since the marketed quantity decreases. For retailer $R$, the standard product price $p_{O R}$ first increases and then decreases in relation to PPL quality. The latter is a result of two effects: on one hand, when PPL quality increases, marketed PPL quantity decreases leading to an increase in the standard product price marketed by $R$ On the other hand, marketed standard product quantity increases leading to a decrease in this price.

It is also interesting to note that the standard product is priced at a lower level than the other retailers. Indeed, the creation of the PPL modifies the behavior of the low quality segment, thereby leading retailer $R$ to offer consumers higher (PPL) and lower (standard product) priced products than the other retailers. The low quality product is always more expensive than in the benchmark but price differential decreases as PPL quality increases. 


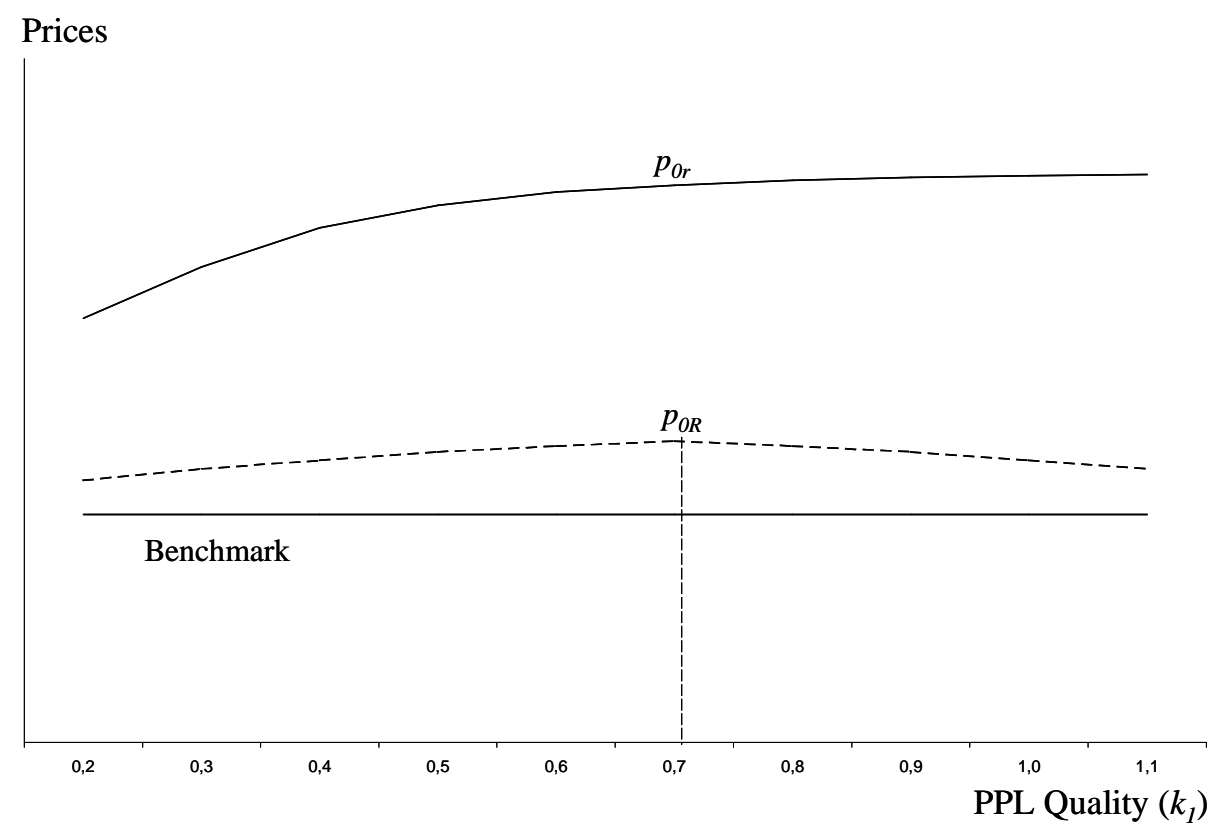

Figure 9 - Standard Product Retail Price according to PPL Quality

If we turn now to the intermediary markets (see Figure 10), we can note two points:

(i) Despite a lower demand for the standard product, the spot market price is always higher than in the benchmark. In fact, the creation of the PPL induces an increase in the spot market price because the decline in the demand for the standard product (linked to higher retail prices) is lower than the decrease in the supply at the upstream level. The latter is a result of the decrease in the number of suppliers (which is reduced from $J$ to $J-G$ ).

(ii) When a private label is set up, the spot market price reaches maximum at an intermediary value of $k_{l}$. Therefore, the spot market price is always higher than the benchmark price but this effect is reduced when the private label quality is either very high or very low. This point can be explained in the following way. With (14) we have seen that the spot market price is increasing in $G$ (since $\alpha$ is increasing in $G$ ) and increasing in $\sum_{i=1}^{R} x_{i}$. When the PPL quality is low, the spot market price increases when $k_{1}$ increases because $G^{*}\left(k_{1}\right)$ increases. When the PPL quality is higher, both $G^{*}\left(k_{1}\right)$ and $\sum_{i=1}^{R} x_{i}$ decrease leading to a decrease of the spot market price. 


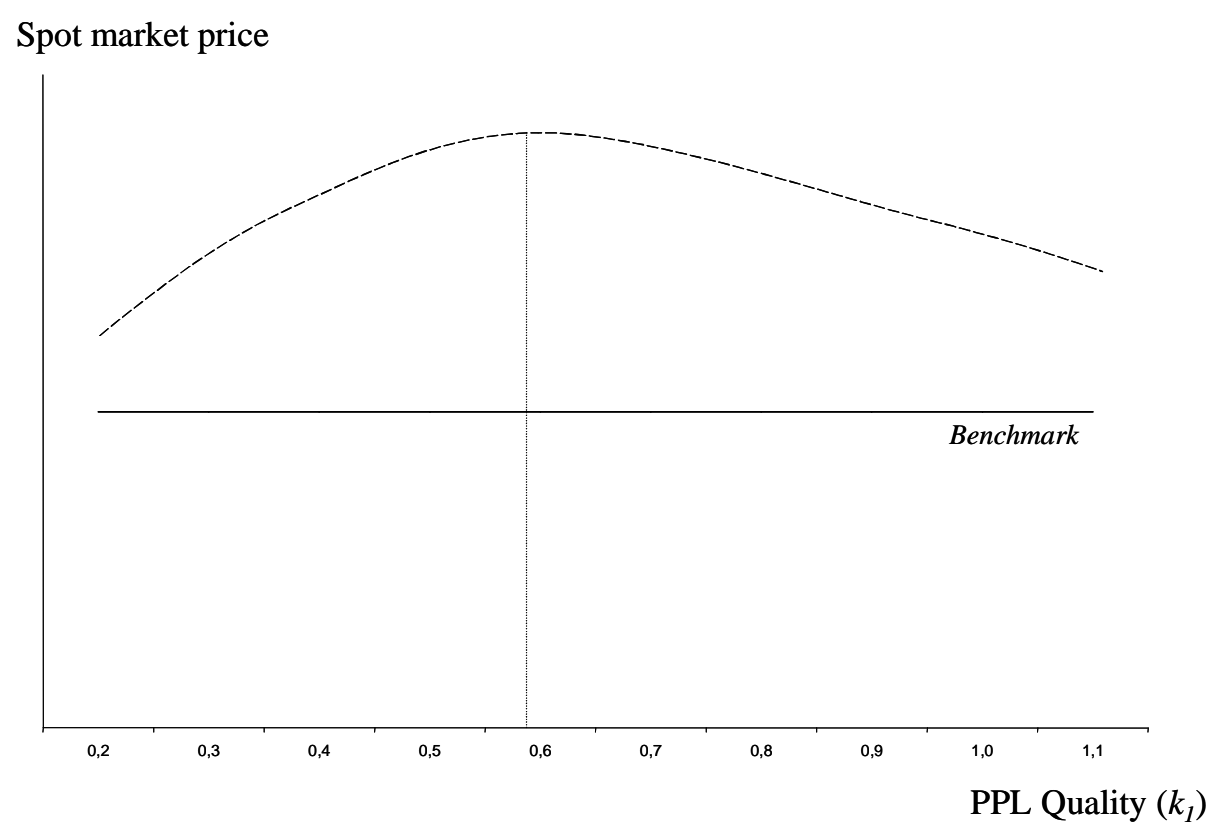

Figure 10 - Spot market price according to PPL Quality

Two cases can be identified with respect to the relationship between captive supplies and spot market prices. When quality differentiation in relation to PPL is not too high, an increase in volume $y_{R}$ of contracts (induced in our model by a decrease in the quality level of PPL) is negatively correlated with the spot market price. When the quality differentiation of the PPL is high, an increase in volume $y_{R}$ of contracts is positively correlated with the spot market price (both simultaneously decrease as $k_{l}$ increases). Of course, the changes in the spot market price have a positive effect on the producers' profits. In fact, this positive externality benefits both upstream producers supplying the spot market and the private label suppliers.

\subsection{Stakeholders' surplus}

Given the previous results, is the creation of the PPL in the interest of the various stakeholders? In order to answer this question, we have to compare the stakeholders' profits with the PPL and in the benchmark situation, and to assess the effects of PPL quality choice by retailer $R$.

\section{(i) Comparison with the benchmark situation}

Retailer $R$, consumers of retailer $R$, the group of $G$ producers and the other producers always do better than in the benchmark irrespective of the quality level of PPL. On the other hand, the other retailers and the consumers of these retailers are penalized by the creation of the PPL. 
Despite the decrease in the number of consumers when the PPL is created (since $p_{0 R} / k_{0}$ is greater than $\left.p_{0} / k_{0}\right)$, retailer $R$ 's profit and the surplus of retailer $R$ 's clientele increase thanks to a better market segmentation.

On the other hand, the increase in the spot market price penalizes the retailers selling only unbranded products (i.e. retailers $r=1$ to $R$-1). Figure 11 clearly shows that the profit of these retailers is always lower than their benchmark profit. The surplus of the clientele of each retailer $r$ decreases (as $p_{0 R} / k_{0}>p_{0} / k_{0}$ ) because of the decrease of marketed quantities.

At the upstream level, all the producers supplying the PPL or the spot market obtain a higher profit than in the benchmark (even though marginal production cost increasing in quality). This result is a consequence of the increase in the spot market price and is explained by the fact that each producer can decide to enter or not the PPL agreement based on the intermediary prices.

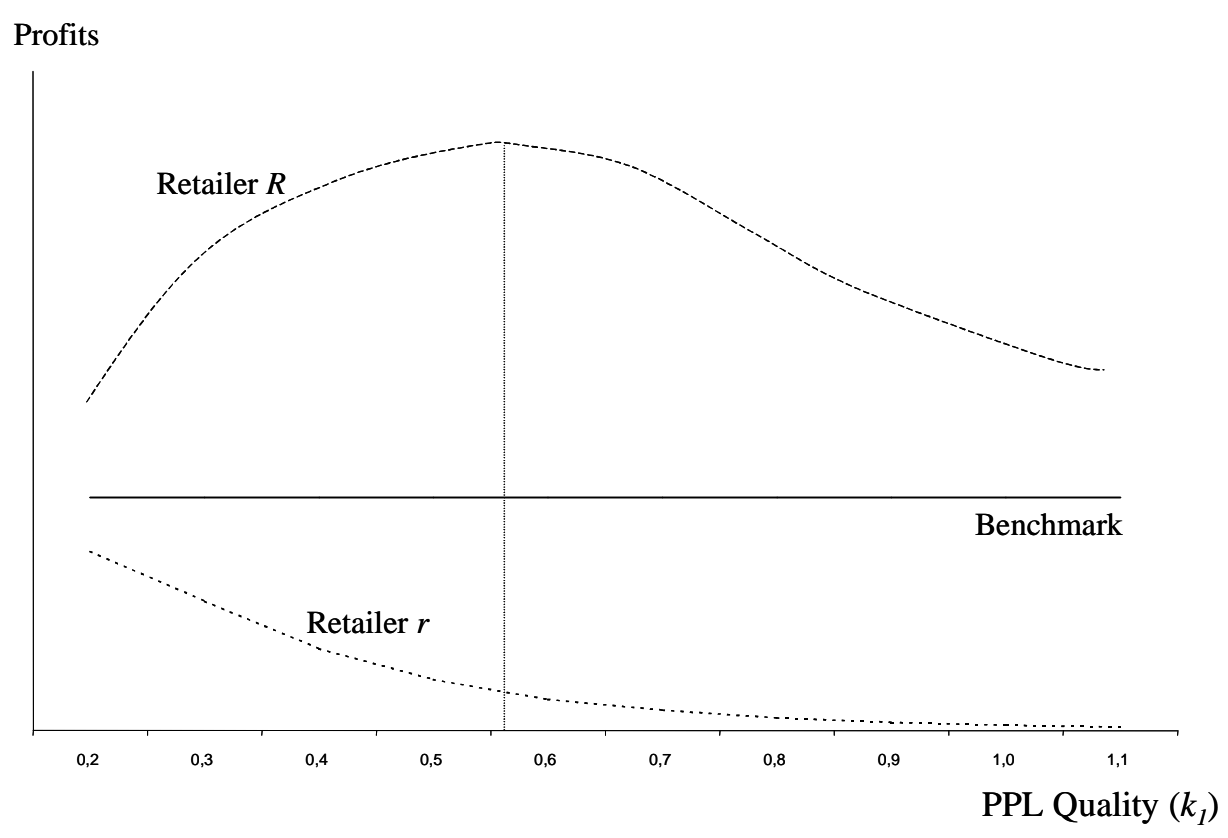

Figure 11 - Retailers' Profits

Finally, the creation of the PPL must be seen as a market segmentation strategy by retailer $R$ and not as a differentiation strategy vis-à-vis the competitors. How, by raising rival supply costs, the segmentation strategy has an effect on the other retailers (even if each retailer is supposed to be a local monopoly like in our model) through its effects on the intermediary markets. 


\section{(ii) The PPL quality choice}

The creation of the PPL improves retailer $R$ 's profit which reaches a maximum at an intermediary value of $k_{1}$. As retailer $R$ 's profit increases in $G$, the value of PPL quality which maximizes its profit is the one for which $G^{*}$ is the greatest. ${ }^{4}$ It turns out, however, that the surplus of retailer $R$ 's consumers is maximized at a lesser amount than retailer R's profit. Figure 12 shows that the PPL quality chosen by retailer $R$ is greater than those chosen by the consumers and lower than those chosen by the producers.

It is also in the interest of the producers to choose a higher quality level than that of the retailers and the consumers because of the type of contract we implicitly selected for the private label supply. We explained that the producers are able to commit to the PPL if and only if $\omega_{1} \geq \omega_{0} \sqrt{c_{1} / c_{0}}$. The payment of extra-costs associated to the higher quality product by the retailer encourages producers to participate in the creation of a premium private label. At this point, the only limiting factor for quality improvement - from the point of view of the producers - is the quantity purchased by the retailer (quantity $y_{R}$ decreases when quality $k_{l}$ increases).

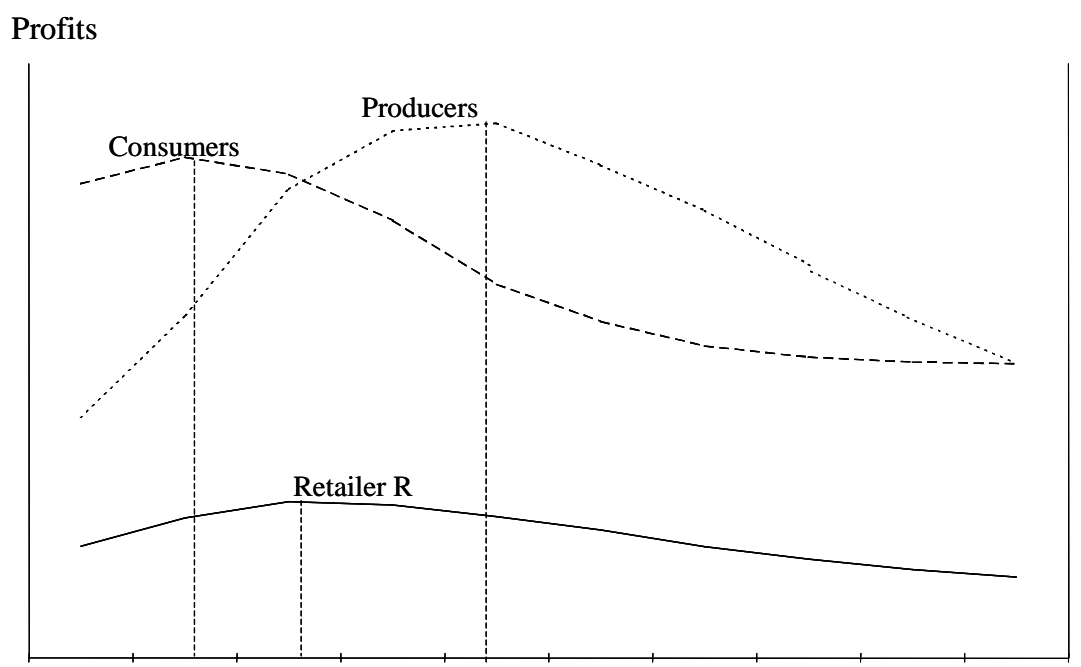

PPL Quality $\left(k_{I}\right)$

Figure 12 - Profits according to PPL Quality

${ }^{4}$ Note that the marginal cost function we use explains the existence of an optimal PPL quality for each stakeholder 


\section{Summary and Conclusions}

An important issue in the food sector, in particular in the meat and fresh produce sectors, is the implementation of high quality private labels. As we have shown in this paper, the market share allocated to the PPL depends on the vertical structure and the extent of supply contracts. We have provided a theoretical framework to shed light on this issue. We have argued that, unlike the private labels implemented in sectors with strong national brands, the PPL in the meat and fresh produce sectors do not aim to increase the bargaining power of the retailers and decrease the value share obtained by their suppliers. Indeed, as shown by the model, the creation of the PPL benefits the upstream producers.

The results give some insights about the real case presented in section 1 and concerning the agreement between Carrefour and one group of beef meat producers in Normandy. This agreement was implemented in 1995 and many empirical analyses showed that it was in the interest of producers to participate to this agreement ${ }^{5}$.

However, many changes arose during the next 10 years. First, the PPL quality level has been improved several times by imposing more stringent production specifications ${ }^{6}$. Secondly, the number of producers involved in the PPL has been decreased (6200 producers in 1998; 5000 in 2002). In our model, this phenomenon can be interpreted as a decrease in the number $G$ of producers involved in the PPL market, which arises when the PPL quality is high enough. Thirdly, the shelf space allocated to the PPL in Carrefour stores has been decreased from $70 \%$ to $55 \%$ between 1998 and 2002. This means that, as shown in Figure 8, the retailer has substituted the standard product ( $x_{R}$ in the model) to the PPL ( $y_{R}$ in the model) when the PPL quality increased. Fourthly, our collected data show that the retail price of the standard product was lower in the Carrefour stores than in stores of other retailers offering only the standard product (see Figure 1 in the introduction). Of course, many factors not taken into account in our analysis can have determined these evolutions in practice (changes in the standard product quality, substitution with other products...). But it is worthwhile to note that these evolutions are compatible with our results and confirm that the PPL quality choice was an important stake for the retailer and the producers.

Another point which emerges from our model is the importance of what happens to intermediary prices to the economic analyses of private labels. The

\footnotetext{
${ }^{5}$ See the website of the group of producers which presents the main features of the production process and the chain agreement with Carrefour: fqrn.viande@ upranormande.org.

${ }^{6}$ The chain agreement between Carrefour and the producers is based on quality criteria. The selection of the carcasses is done according to the mean quality which depends on the age (28 months to 9 years), the weight (more than $300 \mathrm{~kg}$ ), the fattening (2 et 3) and the conformation of animals (according to the European grid : $\mathrm{R}, \mathrm{O}+$ and $\mathrm{O}=$ ). A payment grid is based on these criteria from which depend the profits of the producers.
} 
increase of intermediary prices can be detrimental for retailers (and their customers) who do not implement this type of strategy. Therefore, the economic evaluation of the PPL must take into account the negative externality induced on the whole sector at the spot market level. Note however, that in a long term perspective, such an evolution of the payment of the upstream producers could favor the entry of new producers and lead to a new equilibrium. We did not take into account this possibility in our short term model. ${ }^{7}$

Additional conclusions are as follows:

- Spot market prices are influenced by the PPL quality. This effect is positive for producers but the retailer, by implementing PPL, is able to influence other retailers' profit, even if each retailer is a local monopoly.

- In such a context, an increase in contractual supply can be correlated either positively or negatively with the spot market price. In our model, we cannot obtain a lower spot market price with vertical contracts than without contracts. But we have shown that the spot market price can decrease or increase according to the variation of PPL quality and the volume of contracts.

- Optimal private label quality is not the same for the consumers, the retailers and the producers. Consumers prefer lower PPL quality level than the producers and the retailers. Even if we did not study this issue in this paper, we can infer that, under certain conditions, the producers could accept a decrease in their profit in order to encourage the retailer to increase PPL quality. Such an agreement would result in a PPL quality choice which could be more negative for the consumers.

The conclusions above were obtained for a given level of standard product quality. It is important to note that this quality level, which is determined by the Minimum Quality Standard (MQS) defined by the public authorities, can also influence the strategies and the economic equilibrium in the chain. Indeed, as we have shown in section 3, the equilibrium size of the group of producers decreases when the standard product quality increases. The optimal PPL quality likely depends also on the MQS level. The optimal level of MQS that maximizes social welfare has been studied in several articles (see for instance Ronnen, 1991). It would be interesting for future research to determine the optimal level of MQS in the vertical structure studied in this paper, and the consequences on the PPL quality, the marketed quantities and the stakeholders' profits.

Other extensions would be interesting to consider. In our model, prices and quantities are defined simultaneously and these parameters are simply obtained by equalizing supply and demand on the PPL intermediary market. It would be useful to modify these assumptions in order to investigate more complex negotiation processes. In practice, the price is often determined ex-post whereas the quantities are defined at the first step of the negotiation process. For instance, the payment to upstream producers can at the end of the year, considering all of the services

\footnotetext{
${ }^{7} \mathrm{We}$ thank one of the referees for alerting us to this possibility.
} 
given by the retailer (promotions, positioning in the shelf space...). So it would be useful to examine the consequences of such a negotiation process on the implementation of the PPL agreement.

The quality issue could be also re-considered since it can lead to a hold-up problem. Indeed, when the final demand of PPL is not well known by the contractors, in some circumstances, the producers have to sell on the spot market a high (and more costly) quality product. This risk can reduce the quality investment and modify the positioning and the extent of the PPL. For this reason, it would be interesting to explore the impact of demand uncertainty in various contractual frameworks, especially by focusing, like for instance in de Fraja (1999), on the effects of the sequentiality of the decisions made by each contractor on the outcome of the agreement. 


\section{References}

Azzam, A. "Captive Supplies, Market Conduct, and the Open-Market Price." American Journal of Agricultural Economics 80(1998):76-83.

Bergès-Sennou, F., P. Bontems, and V. Réquillart. "Economics of Private Labels: A Survey of Literature." Journal of Agricultural \& Food Industrial Organization 2(2004): Article 3.

Available at http://www.bepress.com/jafio/vol2/iss1/art3.

Boehlje, M., and L. F. Schrader. "Cooperative Coordination in the Hog-Pork System: examples from Europe and the U.S." Working Paper, Purdue University, Staff Paper, 1998.

Boger, S. "Quality and Contractual Choice: a Transaction Cost Approach to the Polish Hog Market." European Review of Agricultural Economics 28 (2001):241-261.

Bontems, P., S. Monier-Dilhan, and V. Réquillart. "Strategic Effects of Private Labels." European Review of Agricultural Economics 26(1999):147-165.

Champsaur, P. and J. C. Rochet. "Multiproducts Duopolists." Econometrica 57 (1989):533-557.

Chardon, O. and S. Dumartin. " Fidélité aux Enseignes, Fidélité aux Marques : le Choix des Consommateurs.", INSEE Première 609(1998).

Codron, J-M., K. Grunert, E. Giraud-Héraud, L.G. Soler and A. Regmi. Retail Sector Responses to Changing Consumer Preferences: The European Experience, Global markets for high-value food, Agricultural Economic Report, ERS-USDA, Washington DC, 2003.

Connor, J. M., and E. B. Peterson. "Market Structure Determinants of National Brand -Private Label Prices Differences of Manufactured Food Products." The Journal of Industrial Economics 40(1992):157-172.

Corstjens, M., and R. Lal. "Loyalty through Store Brands." Journal of Marketing Research 37(2000):281-291.

Cotterill, R.W., R. Dhar and W. Putsis. "Assessing the Competitive Interaction between Private Labels and National Brands." Journal of Business 73 (2000):109-137.

Dunne, D., and C. Narasimhan. "The New World of Private Labels." Harvard Business Review 77(1999):41-52.

Elam, E. "Cash Forward Contracting versus Hedging of Fed Cattle, and the Impact of Cash Contracting on Cash Prices." Journal of Agricultural and Resource Economics 17(1992):205-217.

Fearne, A. "The Evolution of Partnerships in the Meat Supply Chain: Insights from British Beef Industry." International Journal of Supply Chain Management 3(1998):214-231. 
De Fraja, G. "After You Sir. Hold-Up, Direct Externalities, and Sequential Investment." Games and Economic Behaviour 26(1999):22-39.

Galizzi, G., and L. Venturini. "Vertical Relationships and Coordination in the Food System." Working Paper, Heidelberg, Germany: Physica-Verlag, 1999.

Giraud-Héraud, E., Rouached, L. and L.G. Soler. "Minimum Quality Standards and Premium Private Labels." Cahiers du Laboratoire d'Econométrie de l'Ecole Polytechnique, 2003. Available at http://ceco.polytechnique.fr/.

Hennessy, D.A. "Microeconomics of Agricultural Grading: Impacts on the Marketing Channel." American Journal of Agricultural Economics 78(1996): 1034-43.

Hennessy, D.A. "Information Asymmetry as a Reason for Food Industry Vertical Integration." In The Industrialization of Agriculture : Vertical Coordination in the U.S. Food System, (1998), Ashgate Publishing, Adelshort, U.K.

Love, H.A., and D.M. Burton. "A Strategic Rationale for Captive Supplies." Journal of Agricultural and Resource Economics 17(1999):205-217.

Mazé, A. "Retailers' Labeling Strategies: Contract Design, Organisational Change and Learning." Chain and Network Science (2002):33-45.

Mills, D.E. "Why Retailers Sell Private Labels." Journal of Economics \& Management Strategy 4(1995):509-528.

Mills, D.E. "Private Labels and Manufacturer Counterstrategies." European Review of Agricultural Economics 26(1999):125-145.

Motta, M. "Endogenous Quality Choice: Price vs. Quantity Competition." The Journal of Industrial Economics 2(1993):113-132.

Mussa, M., and S. Rosen. "Monopoly and Product Quality." Journal of Economic Theory 18(1978):301-317.

Raju, J.S., R. Sethuraman and S.K. Dhar. "National Brand-Store Brand Price Differential and Store Brand Market Share." Pricing Theory and Practice: an International Journal 3(1995):17-24.

Ronnen, U. "Minimum Quality Standars, Fixed Costs, and Competition." Rand Journal of Economics 22(1991):490-504.

Schroeder, T.C., R. Jones, J. Mintert, and A.P. Barkley. "The Impact of Forward Contracting on Fed Cattle Transaction Prices." Review of Agricultural Economics 15(1993):325-337.

Slade, M.E. "Product Rivalry with Multiple Strategic Weapons: An Analysis of Price and Advertising Competition." Journal of Economics and Management Strategy 4(1995):445-476.

Vetter, H., and K. Korantininis. "Moral Hazard, Vertical Integration, and Public Monitoring in Credence Goods." European Review of Agricultural Economics 29(2002):271-279. 
Ward, C.E., S.R. Koontz, and T.C. Schroeder. "Impacts of Captive Supplies on Fed Cattle Transaction Prices." Journal of Agricultural and Resource Economics 23(1998):494-514.

Xia, T., and R. Sexton. "The Competitive Implications of Top-of-the-Market and Related Contract-Pricing Clauses." American Journal of Agricultural Economics 86(2004):124-138.

Zhang, M., and R. Sexton. "Captive Supplies and the Cash Market Price: A Spatial Markets Approach." Journal of Agricultural and Resource Economics 25(2000):88-108.

Ziggers, G. W., and J. Trienekens. "Quality assurance in food and agribusiness supply chains: Developing successful partnerships." International Journal of Production Economics 60/61(1999):271-280. 
Copyright of Journal of Agricultural \& Food Industrial Organization is the property of Berkeley Electronic Press and its content may not be copied or emailed to multiple sites or posted to a listserv without the copyright holder's express written permission. However, users may print, download, or email articles for individual use. 